\title{
The mental health consumer movement and peer providers in Israel
}

\author{
G. S. Moran \\ Social Work, Ben-Gurion University of the Negev, Beer-Sheva, Israel
}

\begin{abstract}
Self-help peer-support groups in Israel emerged in the 1980s and, over time, dynamically interacted and co-developed with the statutory mental health (MH) system. In this editorial, I outline historical milestones of how the evolution of the Israeli mental health system was influenced by the consumer movement. A brief depiction of the consumer movement history. At first, consumers operated outside of the mainstream MH system. Gradually, consumer groups and institutional personnel joined efforts towards community integration and enhancement of quality of life, pushing forward a person-centered recovery orientation. In turn, some administrators and key stakeholders in rehabilitation community services grew to value the impact of knowledge-by-experience in contemporary mental health care. In this context, over the past decade, peer roles were developed in the mental health system, including consumer-providers in community services and peer specialists in inpatient psychiatric hospitals. The insertion of peer roles into the mainstream $\mathrm{MH}$ system is far-reaching, including the placement of a peer-project coordinator within the ministry of health. I describe the unique contribution of peers, as experts-by-experience, to mainstream professional knowledge and practice. I also highlight the potential challenges involved when peer models of care are added to traditional medical models of care. The Israeli case demonstrates how the consumer movement can play an active role in MH systems and be acknowledged and recognised as a partner for changing policy, practice and reshaping formal institutions. In addition, they play a vital role in the development of peer-support services.
\end{abstract}

Received 25 August 2017; Accepted 12 March 2018; First published online 16 April 2018

Key words: Community mental health, models/theories of psychiatry, quality of care, rating scale.

The consumer movement and peer-support roles developed in parallel to the historical maturation of the Israeli mental health system. The consumer movement is based on the premise that personal subjective experience provides valuable knowledge which is important for policies and practices in mental health. The impact of the consumer movement on mainstream institutions can perhaps be appreciated through the permeation of the term Mitmoded (in Hebrew) meaning a coper (Rofe, 1998; Oren, 2007) as a substitute for the term mentally ill (in Hebrew mentally ill translates to 'sickness of the soul') commonly used to address individuals with psychiatric disorders and disabilities. Mitmoded is by now a familiar term to most $\mathrm{MH}$ practitioners and administrators.

The use of this wording connotes a recoveryoriented/person-first approach, paralleling similar recovery approaches in other countries. It represents a proactive state towards one's life in the aftermath of mental illness and a commitment on behalf of professionals to support individuals in their recovery

Address for correspondence: G. S. Moran, Social Work, Ben-Gurion University of the Negev, Beer-Sheva 84105, Israel.

(Email: galiam@bgu.ac.il) processes and their striving for personal life goals (Anthony, 1993; Leamy et al. 2011).

In this editorial, I briefly describe the historical evolution of the $\mathrm{MH}$ system in Israel and the role that consumer movement and family members played in it. I then describe two key peer-support roles developed over the past decade and highlight their potentiality and pitfalls. Noteworthy, there is a lack of documentation of the consumer movement and peer support. Thus, this editorial is based on having accumulated informal, internal and media documentations, papers of opinion, interviews with stakeholders and involves the sole interpretation of the author. I use the terminology consumers and service users interchangeably throughout this text, which are the Hebrew terms most commonly used in Israel.

Until the 1980s: institutional period and the medical model

In the first few decades after the establishment of the State of Israel in 1948, government efforts focused on supporting individuals in acute states of mental illnesses, such as florid psychoses and major depressive episodes. The Ministry of Health invested resources to 
enlarge the number of psychiatric beds and establish psychiatric hospital services (Aviram, 1996; Levy, 2010). This period of time is characterised by an institutionalising orientation and dominance of a medical model.

Around 1980, consumer-led and self-help activities begin to form in response to frustrations from the mental health system (Lachman, 1998). Consumers and family members formed autonomous self-help groups and organisations independent of policy makers and professionals. Among the first such groups was Malam ('mitmodedim lema'an mitmodedim', i.e. copers for copers) (Rofe, 1998). Perhaps the most pressing needs of these organised activities were to share and voice their common experiences and grievances. The motivation was to shift from a passive sense of helplessness to an active mode, operating for the sake of oneself or for other mental health service users (Rofe, 1998).

\section{Until the 1990s: deinstitutionalisation, structural reform and changes in legislation}

Over the next decade and up to the 1990s, economic conditions improved and, similar to policies in other Western countries (although lagging behind them), Israeli $\mathrm{MH}$ policy veered to deinstitutionalisation and more attention was put on developing outpatient services (Aviram, 1996).

This decade also witnessed legislative milestones involving the rights of patients and individuals with disabilities. The first milestone was the enactment of the mental patient rights law which grounded the rights of mental patients with regard to psychiatric treatment and hospitalisation. Further legislation involved the equal rights law for individuals with disabilities, to promote equality, prevent discrimination and support the integration of individuals with disabilities in society (ERD, 1998). A council comprised and headed by individuals with disabilities was formed to monitor and advise on the implementation of this law, indicating the increasing acknowledgement of service users' views.

Importantly, in 1994, a major reform was enacted through legislation for health insurance to all citizens and residents. This law ensures that all residents have basic health-care insurance. However the law excluded mental health services which lingered behind, under the responsibility of the Ministry of Health, with fewer economic resources and services, and were segregated from the general health care. In this decade, consumers from multiple forums and organisations have become active in advocacy for systems change. Notably, enduring pressures by Ozma - the national forum of family members of mentally disabled helped to promote legislation for mental health (Ozma, n.d.).

\section{Until 2000: rehabilitation reform}

The gap between health and mental-health legislation drove the consumer and family members' movements to act together with professionals and administrators to make a change. In 2001, the enduring commitment of Israeli parliament member Tamar Goz'ansky together with pressure from family members and users of services, legislators, administrators and $\mathrm{MH}$ professionals, contributed to the enactment of the Rehabilitation for the Mentally Disabled law (RMD, 2001; Aviram, 2010). The RMD law is an important component in the long overdue $\mathrm{MH}$ reform. It provides a package of rehabilitation services and programs including housing, employment, adult education, social and leisure time activity, assistance to families, dental care and case management. Levels of hospitalisation have dropped significantly since its enactment, pushing forward the country's efforts to treatment and care within the community (Shershevsky, 2006; Aviram et al. 2007; Aviram, 2010).

Under the RMD law, a national council was established which monitors the implementation of the law and advises the government on how to further develop rehabilitation services for the mentally disabled. A major focus was the development of residential and occupational services in the community. The council includes individuals with mental disabilities as well as family members, some of whom served as its directors.

In addition to these major policy influences, the personal experiences of professionals with a lived experience of mental illness begin to be heard. These individuals share their concerns with the $\mathrm{MH}$ system and address problems of stigma and suicidality (Katzanelson-Bank, 1995; Rofe, 1998; Harris, 2012).

From 2000 to 2010: development of recovery-oriented care and enhanced involvement of consumers in shaping practices and policy

Around the turn of the century, joint initiatives of consumer activists and welfare/health institutions have developed. One such example is Benafshenu, an initiative that established information centers for service users and family members and conducted educational anti-stigma meetings in which consumers share their personal story with target audiences (practitioners, 
families, administrators, youth, general public) to erode stigma and allow personal contact (Shor, 2008).

Moreover, under the establishment of the RMD law, additional consumer-voice projects evolve. One example is the consumer-surveyors project which trains consumers in conducting satisfaction surveys of residential and occupational services as part of their vocational rehabilitation. The consumersurveyors cover numerous services serving thousands of mental health consumers. The survey outcomes have been used to provide feedback to service providers which help modify services in order to enhance their quality (Moran et al. 2017, 2018; Westman et al. in press).

In this period of time, the vision of recoveryoriented care (Anthony, 1993; Lachman, 2000; Oren, 2007) has been recognised in Israel by both policy and higher education. Recovery-oriented and personcentered interventions became a focus of attention, including the development of evidence-based practices known to effectively enhance consumers' quality of life (Farkas et al. 2005; Leamy et al. 2011). A range of interventions have been developed in Hebrew or adapted to Hebrew, including illness management and recovery, cognitive-dynamic interventions, self-advocacy, psychoeducational interventions, narrative enhancement therapy, readiness and family service centres (e.g., Hadas-Lidor \& Lachman, 2007; Moran, 2011; Yamin et al. 2012; Shalev, 2017). These interventions and curricula integrate consumer perspectives and are taught at some universities, at the continuingeducation school of rehabilitation and counseling centres across the country.

The recovery vision coincides with some of the consumer movement goals, emphasising a person-first approach and individually-tailored care. A dialogue between $\mathrm{MH}$ consumers, educators, professionals and students permeates these different courses through invited discussions with service users and guest speakers in classes. In addition, designated courses for mental health consumers were developed and run at the Hebrew University and University of Haifa, where consumers were encouraged to voice themselves and their perceptions about improving mental health services (e.g., Haf'el course). At least five courses of this sort were held which formed the infrastructure for graduates to later take active roles in shaping policy and practices. In parallel consumer and family member representatives were invited to take part in different forums that influence policy (i.e. governmental mental health committees, Israel's psychiatric rehabilitation association, the mental health reform committee). During these years a group of consumer activists also formed the consumer-provider training program (Oren, 2007) described below.
From 2010 to 2016: The finalization of MH reform legislation and embracement of peer positions in the government

Enduring pressure from consumer and family member organisations to finalise the mental health reform mounted during this period, through the press and the courts (Ozma, n.d.; Tzin, 2011). With other stakeholders, including parliament members, the reform was finally completed in 2015: a merger of mental health care with general health-care insurance. This reform ends the segregation between health and mental health sectors in the country. Currently, in a transitional phase, it is expected to provide higher-quality $\mathrm{MH}$ community services.

In these recent years, consumers (e.g., Tzin, 2011) and family members have regularly voiced their views and concerns through personal, professional and political platforms orally, in writing and through the electronic media (many examples appear in Lishma, n.d.; Malam, n.d.; Maman, n.d. and Ozma, n.d.). An increasing number of individuals with a lived experience of mental illness pursue higher education and research focusing on the study of personal experiences as consumers and professional providers (e.g., Goldberg et al. 2015; Bril-Barniv et al. 2016).

In addition, new alternatives to conventional treatment have been initiated in collaboration with consumers, such as the Soteria House - a peer-based alternative to hospitalisation in the vicinity of Jerusalem. Currently, consumers search for additional alternative models of mental health, exemplified by workshops at the Beer Sheva mental health center, where a group of consumers and professionals learn from initiatives such as the Finnish model of Open Dialogue and the Hearing Voices network model in the USA.

The consumer's voice is also increasingly embraced and integrated into the government. A position was opened for a peer-project initiator in the mental health rehabilitation division in the ministry of health. This position is filled by a consumer activist with a lived experience of mental illness. It provides an opportunity to develop peer-led projects, such as the peerspecialist project described in the next section.

\section{Peer services in Israel: consumer-providers and peer specialists}

Israel now has several opportunities for training of consumers in different roles based on experiencebased-knowledge, supported by the ministry of health (see NSMHRIR Hebrew website: https://www.ono.ac. $\mathrm{il} /$ schools2/health/national-school-for-mental-healthrehabilitation). In these roles, the credibility of the 
peer-supporter derives from their personal knowledge on recovery processes and their sense of camaraderie and empathy towards others in similar conditions. I will focus on two major roles for peer supporters within the mental health system: consumer-providers in community services and peer specialists in psychiatric wards.

\section{The consumer-provider program}

A consumer-provider training was designed and initiated by a small group of consumer-activists with the mission to turn one's personal knowledge on recovery into a rehabilitation expertise which can be provided to mental health service users (Oren, 2007). Over time, it became the largest formal peer-service organisation, integrating consumers as providers into mental health rehabilitation services across Israel.

The consumer-provider training is funded by the Ministry of Health and takes place in the national school of mental health rehabilitation and recovery (see NSMHRIR website) in Kiryat Ono. Training includes 20 weekly full-day study workshops for a group of mental health consumers. Topics, tasks and assignments relate to mental health rehabilitation systems, stigma, self-disclosure and recovery. Topic presentations are followed by group process facilitated by a consumer and a $\mathrm{MH}$ practitioner. Following the successful completion of the course, consumers can be employed in different mental health residential and occupational community services. In addition, if interested, they are eligible to receive ongoing supervision through Yozma-Derech Halev, a consumer-provider supervision program (Merzer-Sapir et al. 2009; Cohen, 2011).

Hundreds of consumer-providers have been trained and employed in different geographical areas around the country, many of which receive ongoing supervision (A. Gefen, personal communication, 2017). Consumer-providers often provide personal support, mentorship and tangible help to service recipients. Results from a recent survey found that consumerproviders support and serve as role models for service recipients; directors of services acknowledged the unique added value that consumer-providers bring to their MH services (Katz et al. 2013).

The motivations that drive consumers to be employed as providers involve, for many peers, a sense of personal mission to give back or change the system, as well as motivations for personal development and regaining work status (Singer, 2010). In this role, self-disclosure and identity are a recurring topic of discussion. The decision of when and what to self-disclose is often impacted by self-stigma and public-stigma as peers interface with different service contexts (Singer, 2010; Katz et al. 2013).

\section{The peer-specialist program}

The peer-specialist project (named Amitim Mumhim in Hebrew) was developed in collaboration with consumer-led groups with the National Social Security Institute (Bituch L'eumi) under the peerproject initiator at the Ministry of Health. This initiative extends peer-support roles to treatment settings. The project was launched in 2015, with a group of 15 peer providers who were trained and placed in two psychiatric hospital sites in the South and in the North of Israel.

Peer specialists work in different open and closed wards of the hospitals and perform multiple tasks. For example, they spend unstructured time conversing and contacting patients on the wards; hold personal meetings, facilitate groups on specific topics (e.g., illness management and recovery intervention/expressive arts), and participate in family consultations. Peer specialists are integrated with the staff, participate in staff meetings, consultations and rehabilitation committees. They are involved in decision-making processes about the allocation of rehabilitation resources to consumers after discharge.

While this pilot project is still in process, emerging qualitative data show that peer specialists can benefit patients in these hospital settings. Interviews with staff show that daily contact between staff and peer specialist created new opportunities for communication that enriched their understanding of the complexity of mental health conditions and appreciation of the struggles in recovery (Chezkner, 2016). For example, in some instances, peer specialists brought to the table the consumer's voice, impacting decision-making processes regarding the allocation of services such as housing, vocational and health services after discharge (RMD, 2001; Chezkner, 2016). More systematic and comprehensive data are expected from this project in the future.

\section{Challenges to peer work in $\mathrm{MH}$}

With the growing integration of consumers in $\mathrm{MH}$ services, new challenges emerge. One of the challenges involves the peer-worker identity. The interface with $\mathrm{MH}$ services raises questions and confusion regarding the occupational identity and clarity about their role in various services and settings. Important issues for consumer providers and peer specialists include their unique competencies and disclosure (with whom, timeliness, appropriateness, etc.). Such questions impact the training of peers and lead to ongoing examination and development of its conceptualisation (Goldberg et al. 2015; Legere \& Farkas, 2016; Bendas-Jacob, 2017; NSMHRIR, 2017 course for consumers-as-providers Website (Hebrew)). 
In addition, situational/environmental conditions may vary across settings and influence the optimal expression of peer providers in their peer roles. For example, while rehabilitation services in the community have been exposed to the consumer movement for a relatively long time, treatment settings tend to be less aware and less open to the notion of $\mathrm{MH}$ peer providers. Psychiatric hospitals/facilities have historically had little contact with the consumer movement, and thus may be less prepared for the assimilation of peer roles and their consumer perspective. This is understandable, given the inherent contradictions between peer models and traditional medical model that is salient in $\mathrm{MH}$ structures. The peer role - in its purest form, is a contributor of knowledge-by-experience to the professional scholastic body of knowledge (Borkman, 1976, 1990). Naturally, there is a risk of dilution of the peer role's distinct potential due to its vulnerable position prone to 'co-optation' - a 'state of tension between formal authority and social power' (Selznick, 1948, p. 35, see also Thompson \& Coskuner-Balli, 2007; Baur \& Schmitz, 2012).

Some strategies that help strengthen peer roles include continued peer-training/supervision, maintaining connection with consumer-activist organisations and developing a clear notion of what it means to be and act as a peer provider in these settings (Moran, 2011; Moran et al. 2012, 2013).

Finally, beyond questions of job definition, there is also the issue of effectiveness. While much development of peer roles has been conducted in the Israeli mental health services, so far there has been lack of study of the end results of peer roles. There is need to systematically examine what recipients of peer services have to say about peer-support services and what are the outcomes of these newly developed roles (Lachman et al. 2017).

\section{Summary and conclusion}

Consumer-led self-help and peer-support activities emerged in Israel during the 1980s stemming from a sense of frustration with $\mathrm{MH}$ services and a need for solidarity. Self-help/peer support and activist groups formed, broke and reunited, pushing agendas to enhance services and fight stigma in $\mathrm{MH}$ care (e.g., see Rofe, 1998; Perry, 2000; Alperovitz, 2002; Singer, 2010). Over time, consumer activists developed collaborations with $\mathrm{MH}$ administration with the joint goal of enhancing the quality of services, human rights and person-centredness.

Overall, the consumer movement plays a vital role as a partner in shaping policy and services. The implementation of peer roles has brought the consumer perspective into traditional mental health and has provided service recipients with knowledge by experience to complement clinical and academic knowledge. Continued involvement of consumers in the shaping of peer services is vital for its future success. In addition, further developing peer occupational tracks, through training and supervision, increasing fidelity of peer-support roles and monitoring of outcomes are important.

\section{Acknowledgements}

I would like to thank Professor Max Lachman for useful discussions and comments in preparation of this article and to Ms. Miriam Goldberg (MSW) in reviewing it.

\section{References}

Alperovitz S (2002). About the consumer movement. Israeli Journal of Psychiatry 39, 3-7.

Anthony WA (1993). Recovery from mental illness: the guiding vision of the mental health system in the 1990s. Innovations and Research 2, 17-24.

Aviram U (1996). Mental health services in Israel at a crossroads: Promises and pitfalls of mental health services in the contexts of the new national health insurance. International Journal of Law and Psychiatry 19, 327-372.

Aviram U (2010). Promises and pitfalls on the road to a mental health reform in Israel. Israel Journal of Psychiatry and Related Sciences 3, 171-194.

Aviram U, Guy D, Sykes I (2007). Risk avoidance and missed opportunities in mental health reform: the case of Israel. International Journal of Law and Psychiatry 30, 163-181.

Baur D, Schmitz HP (2012). Corporations and NGOs: when accountability leads to co-optation. Journal of Business Ethics 106, 9-21. doi: 10.1007/s10551-011-1057-9.

Bendas-Jacob J (2017). Evaluation research of the program Peer Specialists Internal report for the National Social Security Institute. Henrietta Szold Institute - Intermediate internal project report.

Borkman TJ (1976). Experiential knowledge: a new concept for the analysis of self-help groups. The Social Service Review 50, 445-456.

Borkman TJ (1990). Experiential, professional, and lay frames of reference. In Working with Self-Help (ed. TJ Powell), pp. 3-30. NASW Press: Silver Spring, MD.

Bril-Barniv S, Moran GS, Naaman A, Roe D, Karnieli-Miller O (2016). A qualitative study examining experiences and dilemmas in concealment and disclosure of people living with serious mental illness. Qualitative Health Research 27, 573-583. doi: 10.1177/1049732316673581.

Chezkner L (2016). Knowledge, Attitudes and Practices of Staff in a Psychiatric Hospital Following Training and Implementation of Recovery Oriented Interventions. A thesis requirement for the completion of a Master Degree in Social Work. 127 pp. Ben-Gurion University, Beer Sheva (in Hebrew).

Cohen B (2011). Mentally ill: hurt and recovering. Retrieved 12 July 2017 from http://www.doctors.co.il/ar/12982.

Equal Rights for Individuals with Disabilities Law (ERD) (1998). Israel Law Code 1858. Jerusalem: Ministry of Justice (in Hebrew). 
Farkas M, Gagne C, Anthony W, Chamberlin J (2005). Implementing recovery oriented evidence based programs: identifying the critical dimensions. Community Mental Health Journal 41, 141-158.

Goldberg M, Hadas-Lidor N, Karnieli-Miller O (2015). From patient to therapatient. Qualitative Health Research 25, 887898. First published date: October-06-2014. doi: 10.1177/ 1049732314553990.

Hadas-Lidor N, Lachman M (eds) (2007). Rehabilitation and Recovery in Mentalhealth - A Reading From Multiple Perspectives - Practice, Policy and Research. Kfar Yona: LITAM Publication, 584 pp.

Harris D (2012). A peer specialist view of suicide, suicidal attempts and prevention. Presented at the 14th European Symposium of Suicide and Suicidal Behavior, Jaffa-Tel Aviv.

Katz I, Pyureko Y, Mor Y, Talias M (2013). Evaluation Study of the Consumer-Provider Program. Jerusalem: Zofnat Institutue, $70 p p$ (in Hebrew).

Katzanelson-Bank D (1995). From both sides of the psychiatric barracade. Sihot 10, 70-74.

Lachman M (1998). Psychosocial rehabilitation in Israel: a point of change? Society and Welfare 18, 203-211 (in Hebrew).

Lachman M (2000). Recovery Paths of Severe Mental Patients. A dissertation for a doctorate in Philosophy, Paul Baerwald School of Social Work and Social Welfare, Hebrew University of Jerusalem, Jerusalem, Israel.

Lachman M, Friedlander-Katz A, Nissan T, Singer Y, Roe D (2017). The consumer's movement in mental health in Israel and around the world: history, contributions to understanding of recovery, and future challenges. In Against All Odds, from Rehabilitation and Recovery in Mentalhealth to Community Integration (ed. N Hadas-Lidor and M Lachman). Kiryat-Ono Academic. In press (in Hebrew).

Leamy M, Bird V, Le Boutillier C, Williams J, Slade M (2011). Conceptual framework for personal recovery in mental health: systematic review and narrative synthesis. The British Journal of Psychiatry 199, 445-452. doi: 10.1192/ bjp.bp.110.083733.

Legere L, Farkas M (2016). Telling my story. International workshop for peer providers. Yozma-Consumer providers and Lishma conference. Tel-Aviv.

Levy S (2010). Hospitalization in Mental Health. Jerusalem: The Knesset, Center for Research and Data, 20 pp (in Hebrew).

LISHMA (n.d.). Integration and empowerment of mental health copers. Retrieved 19 July 2017 from http://lishma.co. il/page.asp?id=15.

MALAM (n.d.). Copers-for-Copers. Retrieved 19 July 2017 from http://www.malam.org.il/.

MAMAN (n.d.). Families of mental copers. NGO. Retrieved 19 July 2017 from http://www.abiliko.co.il/index2.php? $\mathrm{id}=66 \&$ lang=HEB.

Merzer-Sapir V, Harlev B, Moutner S (2009).

Consumer-provider program an old vision becoming a new reality. Israeli Journal of Occupational Therapy 18, 211-231 (in Hebrew).

Moran GS (2011). Training the trainer on Rehabilitation Readiness. ISPRA Bulletin, 17-18. http://ispraisrael.org.il/ Items/00895/IspraNews5.pdf (in Hebrew).
Moran GS, Russinova Z, Gidugu V, Yim JY, Sprauge C (2012). Benefits and mechanisms of peer providers with mental illnesses. Qualitative Health Research 22, 304-319.

Moran GS, Russinova Z, Gidugu V, Yim JY, Gagne C (2013). Challenges experienced by paid peer providers in mental health recovery: a qualitative study. Community Mental Health Journal 49, 281-291.

Moran GS, The Recovery Oriented Peer Provider (ROPP) (2018). Conceptual model and measure. American Journal of Psychiatric Rehabilitation, Accepted.

Moran GS, Westman K, Weissberg E, Melamed S (2017). Perceived assistance in pursuing personal goals and personal recovery among mental health residents across housing services. Psychiatry Research 249, 94-101.

National School for Mental Health Rehabilitation, Integration and Recovery (NSMHRIR) (2017).

Consumers-as-providers course, Academic College, Kiryat ONO. Retrieved 09 March 2018 from http://www.ono.ac.il/ wp-content/uploads/Rehabilitation-school-newsletter-20172018.pdf.

Oren A (2007). From consumers to providers: a story of a bridge. In Rehabilitation and Recovery in Mentalhealth - A Reading from Multiple Perspectives - Practice, Policy and Research (ed. N Hadas Lidor and M Lachman), pp. 105-113. Kfar Yona: LITAM Publication (in Hebrew).

Ozma (n.d.). The national forum of family members of the mentally disabled. Retrieved 19 July 2017 from http://www. ozma.org.il/.

Perry Z (2000). A Virtual Community of the Mentally Ill: A Construction of Personal and Group Identity. A thesis dissertation. Hebrew University of Jerusalem, Jerusalem, Israel.

Rehabilitation of the Mentally Disabled in the Community, Law (RMD) (2001). Israel Law Code, 1746. Jerusalem: Ministry of Justice (in Hebrew). Retrieved 24 July 2017 from https://www.health.gov.il/English/Topics/Mental_Health/ rehabilitation/Pages/default.aspx.

Rofe Z (1998). Coping with "coping" - action versus passivity. Society and Welfare 18, 1, school of Social work, Hebrew University.

Selznick P (1948). The foundation of theory of organization. American Sociologocal Review 13, 25-35.

Shalev A (2017). Meital, advice and support center for families: framework for thought and innovative intervention model. In From Invisibility to Partnership: Paths to Recovery and Coping with Mental Illness in the Family (ed. A Shalev and N Hadas-Lidor), vol. 2, pp. 31-82. Kiryat Ono: Ono Academic College (in Hebrew).

Shershevsky Y (2006). Rehabilitation package of services for mentally disabled persons in the community. In Mental Health Services in Israel: Trends and Issues (ed. U Aviram and Y Ginath), pp. 357-387. Tel-Aviv: Cherikover. (in Hebrew).

Shor R (2008). In Our Souls: An Accessibility Program in Mental Health - An Evaluation Study. Jerusalem: The Social Security Institute, $81 \mathrm{pp}$ (in Hebrew).

Singer Y (2010). The Experience of Transition from A Coper with Persistent Psychiatric Disabilities to a Consumer-Provider. A Master thesis dissertation. Department of Community Mental Health, Mount Carmel, Haifa (in Hebrew). 
Thompson C, Coskuner-Balli G (2007). Countervailing market responses to corporate co-optation and the ideological recruitment of consumption communities. Journal of Consumer Research 34, 135-152.

Tzin I (2011). Mentally ill in waiting line for Health services (Kupot Cholim)? An appeal to Knesset member Shelly Yechimovitz. http://www.maman.org.il/50217/ archive_news (in Hebrew).

Westman K, Weisberg E, Moran GS, Hadas-Lidor N (in press). Consumers' perceptions of staff support in pursuing personal goals and recovery in residential services. In Against All Odds, From Rehabilitation and Recovery in Mentalhealth to Community Integration (ed. N Hadas-Lidor and M Lachman). Kiryat-Ono, Israel: Kiryat-Ono Academic (in Hebrew).

Yamin A, Roe D, Yanos P, Lysaker P (2012). Group-based intervention for the treatment of self stigma among people with severe mental illness Sichot 26, 278-290 (in Hebrew). 